\title{
New genetic context of $\ln u(B)$ composed of two multi-resistance gene clusters in clinical Streptococcus agalactiae ST-19 strains
}

\author{
Kaixin Zhou', Dongan Zhu' ${ }^{2}$, Ying Tao ${ }^{1}$, Lianyan Xie ${ }^{1}$, Lizhong Han ${ }^{1}$, Yibo Zhang ${ }^{3^{*}}$ and Jingyong Sun ${ }^{1 *}$
}

\begin{abstract}
Background: Clindamycin is a lincosamide antibiotic used to treat staphylococcal and streptococcal infections. Reports of clinical Streptococcus agalactiae isolates with the rare lincosamide resistance/macrolide susceptibility $\left(\mathrm{L}^{\mathrm{R}} / \mathrm{M}^{\mathrm{S}}\right)$ phenotype are increasing worldwide. In this study, we characterised three clinical S. agalactiae strains with the unusual $L$ phenotype from China.

Methods: Three clinical S. agalactiae strains, Sag3, Sag27 and Sag4104, with the L phenotype were identified from 186 isolates collected from 2016 to 2018 in Shanghai, China. The MICs of clindamycin, erythromycin, tetracycline, levofloxacin, and penicillin were determined using Etest. PCR for the Inu(B) gene was conducted. Whole genome sequencing and sequence analysis were carried out to investigate the genetic context of Inu(B). Efforts to transfer lincomycin resistance by conjugation and to identify the circular form by inverse PCR were made.

Results: Sag3, Sag27, and Sag4104 were susceptible to erythromycin (MIC $\leq 0.25 \mathrm{mg} / \mathrm{L}$ ) but resistant to clindamycin (MIC $\geq 1 \mathrm{mg} / \mathrm{L}$ ). Inu(B) was found to be responsible for the $L$ phenotype. Inu(B) in Sag3 and Sag27 were chromosomally located in an aadE-spw-Isa(E)-Inu(B) resistance gene cluster adjacent to an upstream 7-kb tet(L)-cat resistance gene cluster. Two resistance gene clusters were flanked by the IS6-like element, IS1216. Sag4104 only contained partial genes of aadE-spw-Isa(E)-Inu(B) resistance gene cluster and was also flanked by IS1216.

Conclusion: These results established the presence of the $L$ phenotype associated with $\operatorname{lnu}(B)$ in clinical $S$. agalactiae isolates in China. The Inu(B)-containing multi-resistance gene cluster possibly acts as a composite transposon flanked by IS1216 and as a vehicle for the dissemination of multidrug resistance among S. agalactiae.
\end{abstract}

Keywords: S. agalactiae, Inu(B), L phenotype, Composite transposon, IS1216

\section{Background}

Streptococcus agalactiae (group B streptococcus) is a leading cause of neonatal sepsis, meningitis, and pneumonia in many countries. It is also an important pathogen among pregnant women, immunocompromised adults, as well as the elderly [1].

\footnotetext{
* Correspondence: yiboguan@126.com; 13671578899@126.com Kaixin zhou was the fisrt author and Dongan Zhu was the co-first author ${ }^{3}$ Department of Hospital infection control, Ruijin Hospital, Shanghai Jiaotong University School of Medicine, 197 Ruijin 2nd Road, Shanghai 200025, China ${ }^{1}$ Department of Clinical Microbiology, Ruijin Hospital, Shanghai Jiaotong University School of Medicine, 197 Ruijin 2nd Road, Shanghai 200025, China Full list of author information is available at the end of the article
}

The lincosamide class of antibacterial agents was first characterised in the 1960s and is now among the twenty most important antibiotic compounds [2,3]. The most clinically relevant lincosamide, clindamycin, is frequently used to treat staphylococcal and streptococcal infections. It is also a feasible option for the treatment of $\beta$ lactamase-producing pathogens and important protozoal diseases, such as malaria [2,4]. Clindamycin treatment has been limited by antimicrobial resistance and gastrointestinal side effects. However, it is effective for the treatment of methicillin-resistant Staphylococcus aureus $[5,6]$, especially for the empirical treatment of CA-MRSA for outpatients with skin and soft tissue infection.

(c) The Author(s). 2019 Open Access This article is distributed under the terms of the Creative Commons Attribution 4.0 International License (http://creativecommons.org/licenses/by/4.0/), which permits unrestricted use, distribution, and reproduction in any medium, provided you give appropriate credit to the original author(s) and the source, provide a link to the Creative Commons license, and indicate if changes were made. The Creative Commons Public Domain Dedication waiver (http://creativecommons.org/publicdomain/zero/1.0/) applies to the data made available in this article, unless otherwise stated. 
Table 1 PCR primers used in this study

\begin{tabular}{llc}
\hline Primer & Sequence $\left(5^{\prime}-3^{\prime}\right)$ & Product size (bp) \\
\hline InuB-F & ACCAAAGGAGAAGGTGACCAA & 584 \\
InuB-R & ACCTTATCTAATCGAGCAGTGGT & \\
$3-\mathrm{F}$ & TTCGATTCCTCGTGCCTGAC & 1877 \\
$3-\mathrm{R}$ & AAGCGAGGTCGTAACTGGTG & \\
Rev-1-F & ACGCCCTGTAACGCTTGTAA & 2571 \\
Rev-1-R & TGCAAAGACCACTGCTCGAT & \\
Rev-2-F & GGTGAACGAAAGCCCACCTA & \\
\hline
\end{tabular}

Resistance to macrolides, lincosamides, and streptogramin B mediated by erm or mef is quite common in streptococci, while isolates characterized by the combination of phenotypic lincosamide resistance and macrolide susceptibility $\left(\mathrm{L}^{\mathrm{R}} / \mathrm{M}^{\mathrm{S}}\right)$ are rare. Specific resistance to lincosamides is mediated by members of the $\ln u$ (previously lin) gene family, which encode nucleotidyltransferases that catalyse the adenylation of lincosamides $[7,8]$. Six types of $\ln u-\ln u(A), \ln u(B), \ln u(C), \ln u(D), \ln u(E)$, and $\ln u(F)$-have been discovered to date [9-13]. Reports of Streptococcus agalactiae with the unusual L phenotype have recently increased in the United States [8], Canada [11], Spain [14], and other countries.

In this study, three clinical S. agalactiae isolates of the unusual L phenotype were identified. The phenotype was mediated by a nucleotidyltransferase expressed by $\ln u(B)$. We investigated the genetic context of $\ln u(B)$ and estimated its possible formation in $S$. agalactiae. To the best of our knowledge, this is the first report on the genetic context of $\operatorname{lnu}(B)$ gene in clinical $S$. agalactiae isolates in China.

\section{Methods}

\section{Bacterial strains and lincosamide resistance gene detection}

Three clinical S. agalactiae strains with the unusual resistance phenotype $\left(\mathrm{L}^{\mathrm{R}} / \mathrm{M}^{\mathrm{S}}\right)$, Sag3, Sag27 and Sag4104, were identified from 186 clinical strains collected from various sample types (including midstream urine, vaginal secretion, and blood) between 2016 to 2018 in Shanghai, China (Ruijin Hospital, School of Medicine, Shanghai Jiaotong University). All the isolates were identified using MALDI-TOF MS (bioMérieux, France), and the minimum inhibitory concentrations (MICs) were determined using VITEK2 automated systems (BioMérieux, France). Sag3 was isolated from the vaginal secretion of a pregnant female outpatient in 2016; Sag27 was isolated from perianal region of a female inpatient after bone marrow transplantation in 2018; and Sag4104 was isolated from urine sample of a female inpatient in 2018. Sag3, Sag27 and Sag4104 were investigated for the lincosamide resistance gene, $\ln u(B)$, by PCR (Table 1 ).

\section{Antimicrobial susceptibility test and conjugal transfer experiments}

The minimum inhibitory concentrations (MICs) of clindamycin, erythromycin, tetracycline, levofloxacin, and penicillin were determined using the Etest (bioMérieux, Marcy-l'Étoile, France). The results were interpreted based on the guidelines of the Clinical and Laboratory Standards Institute (CLSI) [15]. The transfer of lincomycin resistance was attempted from Sag3, Sag27, and Sag4104 $\left(\mathrm{L}^{\mathrm{R}} / \mathrm{M}^{\mathrm{S}}\right)$ to clinical $S$. agalactiae strains $\left(\mathrm{L}^{\mathrm{S}} / \mathrm{M}^{\mathrm{R}}\right)$ by the filter-mating method. Selection was performed with erythromycin $(1 \mu \mathrm{g} / \mathrm{mL})$ and lincomycin $(1 \mu \mathrm{g} / \mathrm{mL})$.

\section{Pulsed-field gel electrophoresis}

Sag3, Sag27, and Sag4104 were digested with SmaI endonuclease and subjected to pulsed-field gel electrophoresis (PFGE), as described in previous studies [16, 17]. Briefly, two or three colonies were picked from a fresh plate of overnight growth and incubated in ToddHewitt broth for $5 \mathrm{~h}$ at $35^{\circ} \mathrm{C}$; this suspension was centrifuged and the pellet was re-suspended in Tris- $\mathrm{NaCl}$ buffer. The agarose-bacterium plugs were made and incubated overnight at $35^{\circ} \mathrm{C}$ in lysis solution. The plugs were washed for several times and digested with suitable nuclease. The chromosomal digests were separated by PFGE. Pulsotypes were clustered on the basis of a cutoff of $70 \%$ similarity.

\section{DNA sequencing and analysis}

Genomic DNA was extracted using the QIAGEN Midi Kit (Qiagen, Hilden, Germany). The DNA of Sag27 was sequenced using the PacBio RS II (Pacific Biosciences, Menlo Park, CA, USA). The reads were de novo assembled using HGAP 3.0 SMRT ${ }^{\mathrm{TM}}$ Pipe. Sag3 and Sag4104 were sequenced using the Illumina HiSeq sequencing

Table 2 Relevant features of the two strains Sag3 and Sag27

\begin{tabular}{|c|c|c|c|c|c|c|c|c|c|c|}
\hline \multirow[t]{2}{*}{ Strain } & \multirow[t]{2}{*}{ Year } & \multirow[t]{2}{*}{ Source } & \multirow[t]{2}{*}{$\mathrm{ST}$} & \multirow[t]{2}{*}{ Serotype } & \multicolumn{5}{|c|}{ MIC (mg/L) } & \multirow[t]{2}{*}{ Resistance genes } \\
\hline & & & & & $E$ & $\mathrm{CM}$ & $\mathrm{TE}$ & LEV & $P$ & \\
\hline Sag3 & 2016 & Vaginal secretion & 19 & III & 0.125 & 8 & 8 & 0.50 & 0.016 & $\ln u(B), \operatorname{ls} a(E), \operatorname{aad} E, \operatorname{cat}, \operatorname{tet}(L), \operatorname{tet}(M)$ \\
\hline Sag27 & 2018 & Perianal region & 19 & III & 0.094 & 12 & 16 & 0.50 & 0.032 & $\ln u(B), \operatorname{aad} E, \operatorname{cat}, \operatorname{tet}(L), \operatorname{tet}(O)$ \\
\hline Sag4104 & 2018 & urine & 19 & III & 0.125 & 8 & 6 & 0.50 & 0.16 & $\ln u(B), \operatorname{ls} a(E), \operatorname{tet}(M)$ \\
\hline
\end{tabular}

E erythromycin, CM clindamycin, TE tetracycline, LEV levofloxacin, $P$ penicillin 
approach. SOAP de novo (http://soap.genomics.org.cn/, v2.01) was used for genome assembly. Sequence similarity was evaluated by BLAST searches (http://www.ncbi. nlm.nih.gov). Open reading frames (ORFs) were predicted using ORF Finder (https://www.ncbi.nlm.nih.gov/ orffinder/). Protein-coding genes were initially identified and annotated using RAST. Antimicrobial resistance genes were identified using ResFinder (https://cge.cbs.dtu. $\mathrm{dk} /$ services/ResFinder/). Multi-locus sequence typing was identified using MLST 2.0 (https://cge.cbs.dtu.dk/services/ MLST/).

\section{Gap closure, circularisation, and integration site of the Inu(B)-carrying fragment}

PCR with primers 3-F and 3-R was used to close the gap between two scaffolds around the $\ln u(B)$-carrying fragment in Sag37. Outward-directed primers (Rev-1-F, Rev1-R, Rev-2-F, and 3-R) were used to detect the circular form of the IS1216-flanked fragments (Table 1; Fig. 2).

\section{Nucleotide sequence accession numbers}

The nucleotide sequences of Sag27/Sag4104 and the $\operatorname{lnu}(B)$-carrying fragment of Sag3 have been deposited at DDBJ/ENA/GenBank under the accession numbers CP031556, SMRZ00000000, and MK102985, respectively.

\section{Results}

Characterisation of rare $\mathrm{L}^{\mathrm{R}} / \mathrm{M}^{\mathrm{S}}$ S. agalactiae isolates

The strains were susceptible (MIC $\leq 0.25 \mathrm{mg} / \mathrm{L}$ ) to erythromycin, but resistant to clindamycin (MIC $\geq 1 \mathrm{mg}$ / L). All the strains were classified as ST-19 and serotype III. PCR and sequencing results showed that strains contained the lincosamide resistance gene, $\ln u(B)$. These results, isolation data, and resistance genes are summarised in Table 2. SmaI-PFGE analysis indicated that the three strains were of different pulsotypes (Fig. 1).

\section{General genomic features and genetic context of Inu(B)}

In the whole genome sequencing analysis, 54 total scaffolds were obtained for Sag3 with a total length of 2,292, $988 \mathrm{bp}$, while 53 scaffolds were obtained for Sag4104 with a total length of $2,188,850 \mathrm{bp}$. The average $\mathrm{G}+\mathrm{C}$ content of Sag3 and Sag4104 was 35.88 and 35.59\%, respectively. The genome of Sag27 comprised a single circular chromosome of 2,205,229 bp in length; the average $\mathrm{G}+\mathrm{C}$ content was $35.71 \%$ and a total of 2229 protein-coding sequences (CDS) were predicted.

Extensive sequence analyses revealed two $\ln u(B)$-carrying fragments in both Sag3 and Sag27. In Sag 27 (CP031556, 136,248-157,861 bp), $\ln u(B)$ was embedded in the $a a d E-s p w-l s a(E)-\ln u(B)$ resistance gene cluster and an additional 7-kb tet(L)-cat resistance gene cluster was detected immediately upstream. The two clusters were flanked by the IS6-like element, IS1216. The whole

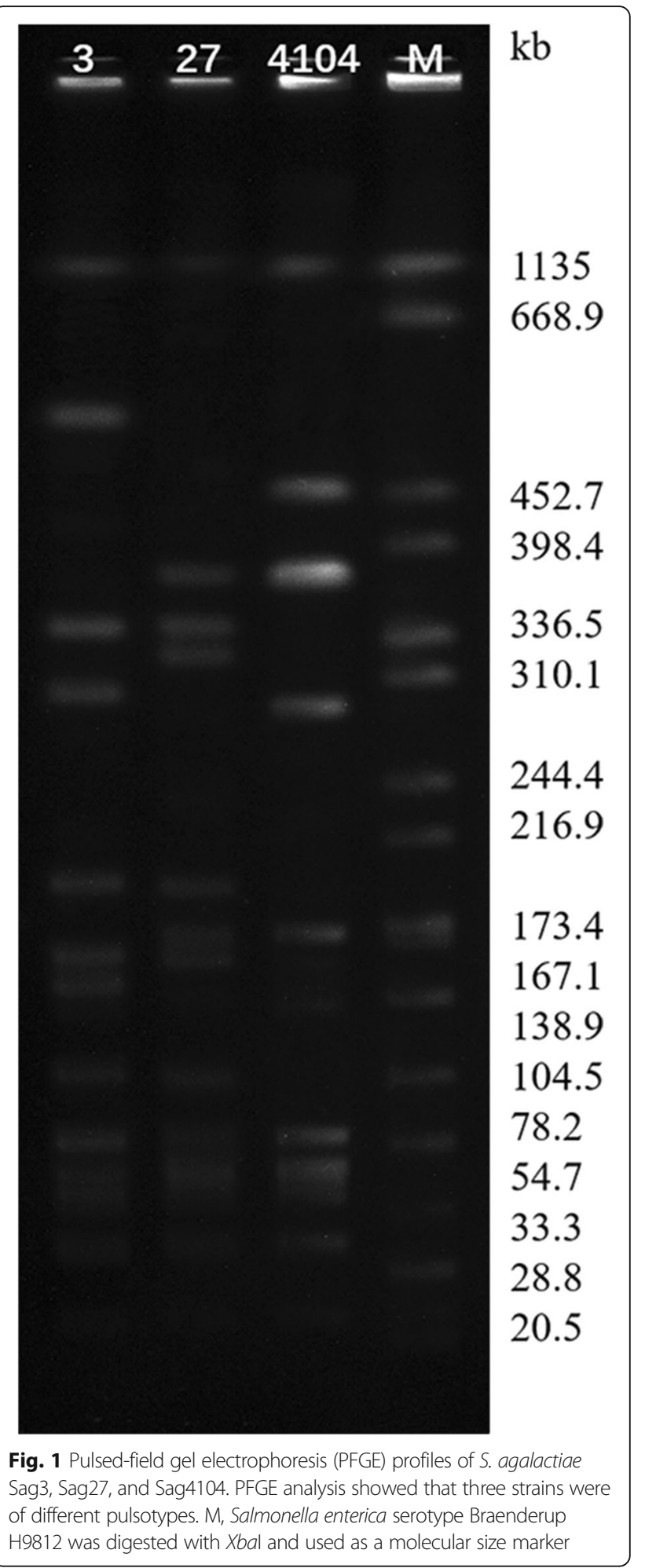

fragment was 21,614 bp. A group II intron inserted into the topoisomerase I gene (topo) was also identified in the fragment, with high similarity to the group II intron En.fm.I2 first found on the Enterococcus faecium plasmid 


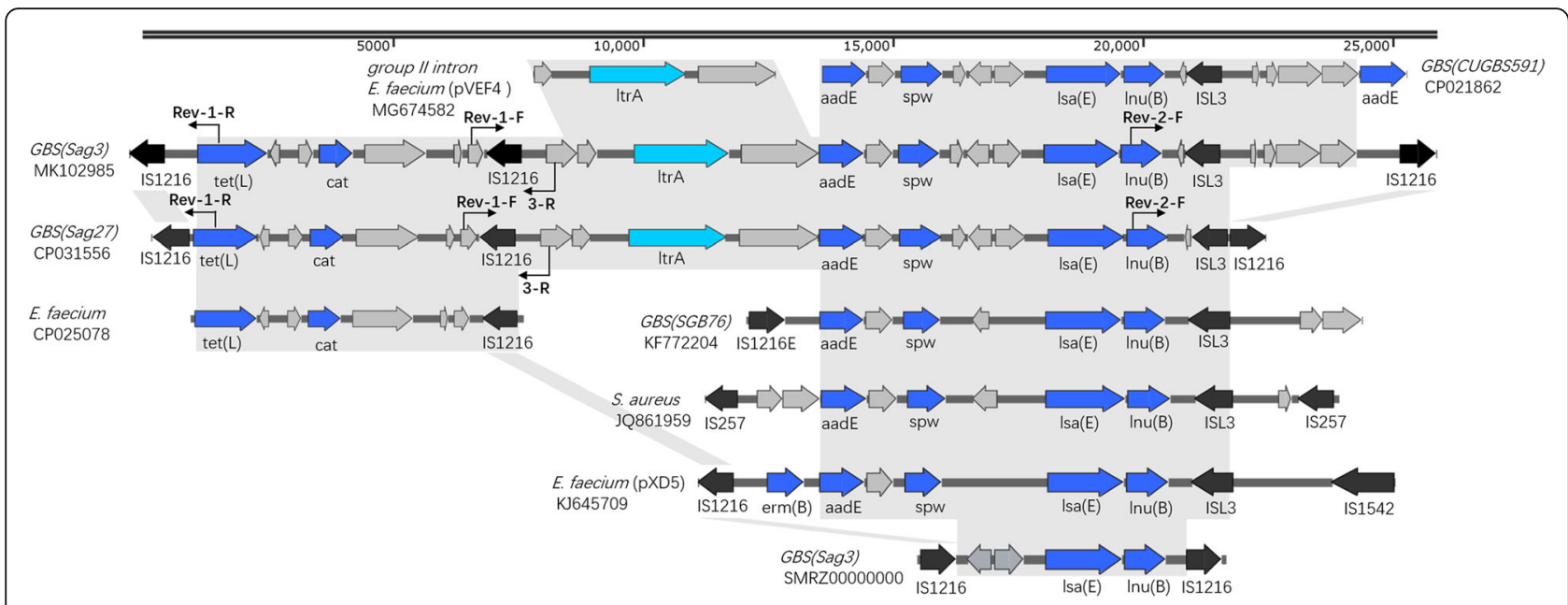

Fig. 2 Schematic representation, drawn to scale, of the Inu(B)-containing multi-resistance gene clusters in Sag3/Sag27/Sag4104 and a comparison of linear DNA against the corresponding regions in different species, including S. agalactiae, Staphylococcus aureus, and E. faecium. The resistance genes are indicated by blue arrows and the insertion sequences are indicated by black arrows. Homologous regions are shaded in grey. Nucleotide sequence identity was at least $95 \%$ in these regions

pVEF4 [18]. Sag4104 only contained partial genes of

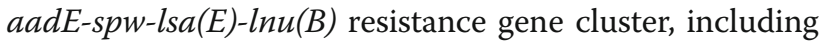
$l s a(E)$ and $\ln u(B)$. The gene cluster was also flanked by the IS6-like element, IS1216.

Comparative genome analyses identified two scaffolds in Sag3 that shared high similarity and contained all resistance genes in the abovementioned fragment in Sag27. Gap closure was performed by PCR. The final spliced fragment was $256,867 \mathrm{bp}$. Although the major drug resistance clusters were similar, there were slight differences at the head and tail regions between the two fragments. There were four additional ORFs at the tail of the fragment in Sag3 (Fig. 1). The gene cluster in Sag4104 also shared high similarity with the fragment in Sag3 and Sag27.

\section{Transferability}

Since insertion sequences (IS) can move resistance genes as part of a composite transposon, a region bound by two copies of the same or related IS that can move as a single unit [19], several conjugal transfer experiments between Sag3/Sag27/Sag4014 and different recipient cells were performed. Even after numerous attempts, no transconjugant was obtained. This indicated that mobilisation of the $\ln u(B)$-carrying fragments does not occur in $S$. agalactiae, or occurs at very low frequencies. Inverse PCR was also performed to identify the circular form of the fragments but was unsuccessful.

\section{Discussion}

Erythromycin and clindamycin are recommended for patients who are allergic to $\beta$-lactams for the prevention or treatment of $S$. agalactiae infections $[8,20]$.
Erythromycin and clindamycin resistance rates in S. agalactiae are rising in several countries, with slight geographical variations, including the United States, Spain, and China [21-24]. Resistance to clindamycin in the absence of erythromycin resistance is relatively rare in $S$. agalactiae; however, the frequency of this phenotype has also increased in recent years $[8,14,25,26]$. Reports of Streptococcus agalactiae with the unusual L phenotype have recently increased in the United States [8], Canada [11], Spain [14], and other countries. We reported three clinical $S$. agalactiae strains with the unusual L phenotype mediated by $\ln u(B)$ in China and further investigated the gene context of $\ln u(B)$.

$\ln u(B)$ was chromosomally embedded in both Sag3 and Sag27 as part of a $a a d E-s p w-l s a(E)-\ln u(B)$ resistance gene cluster, while Sag4104 only contained partial genes of $a a d E-s p w-l s a(E)-\ln u(B)$ resistance gene cluster, including $\operatorname{ls} a(E)$ and $\ln u(B)$. The $\ln u(B)$-containing multi-resistance gene cluster in this study showed high similarity to transposable elements found in $S$. agalactiae, Staphylococcus aureus, E. faecium, and other taxa (Fig. 1), with some differences in insertion sequences in the head and tail (flanked by IS1216, IS1257, or IS1542).

Interestingly, the location of the gene cluster differs among species. The gene cluster was found on plasmids in E. faecium (pXD5 [27], pEF418, etc.) and was embedded either in the chromosome or on the plasmid in $S$. aureus [28]. The gene clusters were only located on the chromosomes of $S$. agalactiae. In particular, the $\ln u(B)$ containing gene cluster was embedded in an integrative and conjugative element (ICE) in CUGBS591 (accession number: CP021862). The transferability of this ICE was not indicated. Coincidentally, ICESsuNC28, a mobile 


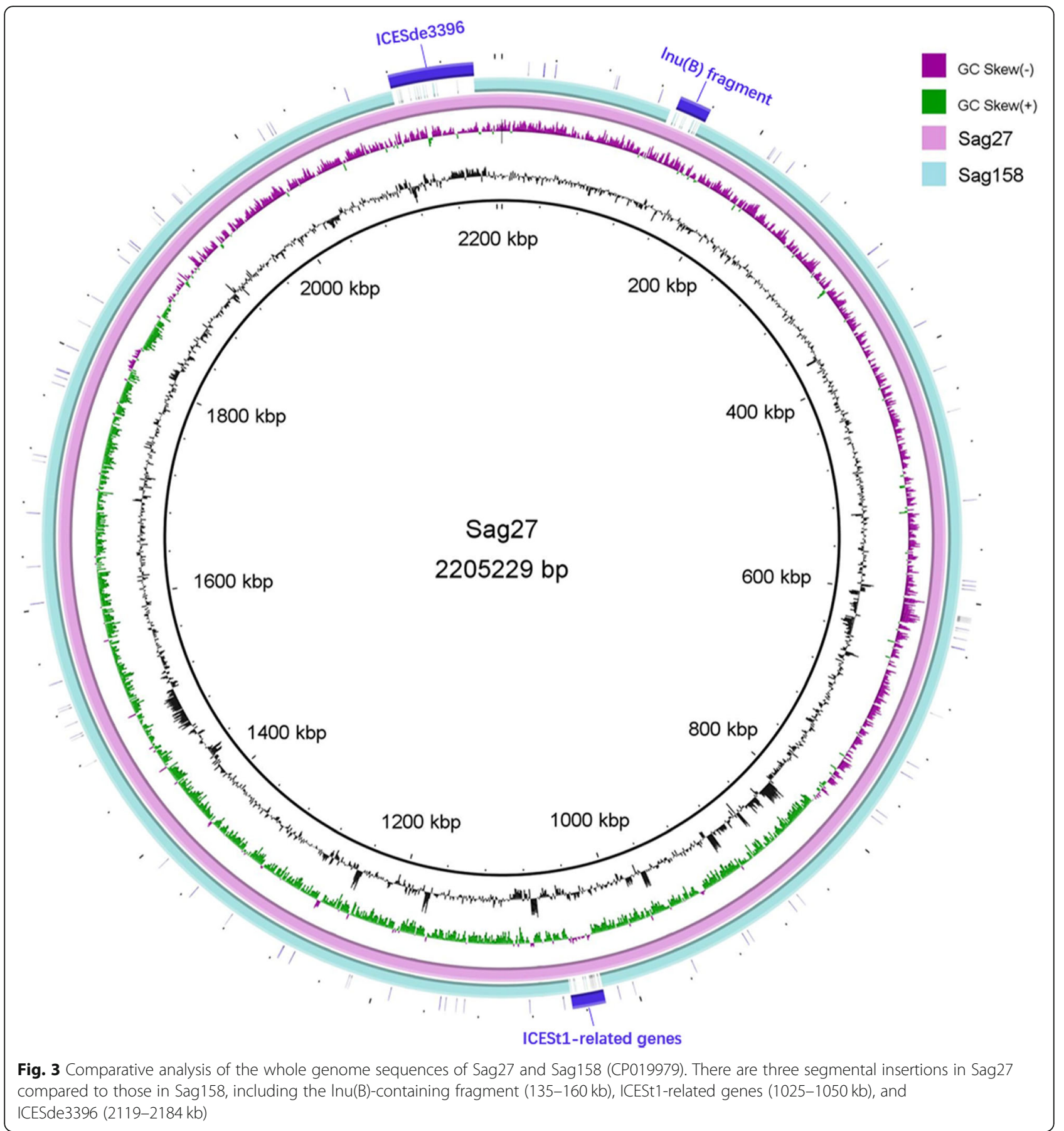

genetic element identified in $S$. suis harbouring the $s p w$ -

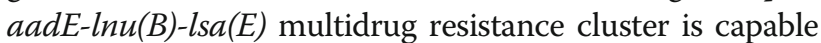
of intraspecific transfer by conjugation [7]. The multidrug resistance cluster likely originated in enterococcal strains and was acquired by staphylococcal and streptococcal species [27]. Although we failed to prove that the $\ln u(B)$ containing gene cluster can be transferred by mating experiments, data analysis suggested that interspecific exchange is possible. Further research is needed to characterise the mechanisms underlying its transfer.

An additional 7-kb tet( $L$ )-cat resistance gene cluster was detected immediately upstream of the $\ln u(B)$-containing multi-resistance gene cluster in Sag3 and Sag4104. It showed high similarity to a plasmid of E. faecium strain LS170308 (CP025078). Few sequences in the GenBank database show high similarity to the tet(L)-cat 
resistance gene cluster. Although the $\ln u(B)$-containing multi-resistance gene cluster has been found in several species, the two gene clusters are not linked together in previously reported genomes. The tandem sequence was identified in both Sag3 and Sag27, indicating that it can be transferred as a unit among $S$. agalactiae.

With respect to the formation of this multi-drug resistance gene, the $\ln u(B)$-containing and tet $(L)$-cat resistance gene clusters both originated from plasmids of enterococcal strains. Different insertion sequences (IS1216, IS257, etc.) in the plasmids formed a "translocatable unit" (TU) bound by two copies of the same IS, which can move as a single unit into plasmids or the chromosome [19]. A TU is preferentially inserted next to an existing copy of the same IS in a recipient molecule via a conserved process [19], which can explain why the tet $(L)$-cat resistance gene cluster flanked by IS1216 was detected immediately upstream of the $\operatorname{lnu}(B)$-containing gene cluster. Thus, once a TU with a resistance gene(s) is inserted, it might become a recruiter for other TUs, resulting in the formation a multidrug resistance gene cluster.

Sag3, Sag27, and Sag4104 were ST-19, the most frequent ST of $S$. agalactiae in China [29]. The genome of Sag27 showed striking similarity (94\%) to that of another $S$. agalactiae strain, Sag158 (accession number: CP019979), previously described by us [30] (Fig. 2). Three segmental insertions in Sag27 were detected in comparison with Sag158, including the $\operatorname{lnu}(\mathrm{B})$-containing fragment (135$160 \mathrm{~kb})$, ICESt1-related genes $(1025-1050 \mathrm{~kb})$, and ICESde3396 (2119-2184 kb). (Figure 3) The $\ln u(B)$-containing multi-resistance gene cluster possibly acts as a composite transposon flanked by IS1216 and as a vehicle for the dissemination of multidrug resistance among ST19 S. agalactiae.

\section{Conclusion}

We reported three clinical $S$. agalactiae strains with the unusual resistance phenotype $\mathrm{L}^{\mathrm{R}} / \mathrm{M}^{\mathrm{S}}$ mediated by $\ln u(B)$. Our analyses of the genetic context and transferability of $\ln u(B)$ provide insight into the recent spread of rare resistance phenotypes in S. agalactiae.

\section{Abbreviations}

CLSI: Clinical and Laboratory Standards Institute; ICE: Integrative and conjugative element; IS: Insertion sequences; MIC: The minimum inhibitory concentrations; ORF: Open reading frame; PFGE: Pulsed-field gel electrophoresis; TU: Translocatable unit

\section{Acknowledgements}

Not applicable.

\section{Authors' contributions}

All authors have contributed equally to this work. All authors read and approved the final manuscript.

\section{Funding}

This work was funded by Outstanding Leaders Training Program of Pudong Health Bureau of Shanghai (Grant No. PWRI2016-04) and Gaofeng Clinical Medicine Grant Support (project number2017269).

\section{Availability of data and materials}

The nucleotide sequences of Sag27/Sag4104 and the Inu(B)-carrying fragment of Sag3 have been deposited at DDBJ/ENA/GenBank under the accession numbers CP031556, SMRZ00000000, and MK102985, respectively.

\section{Ethics approval and consent to participate}

This study was approved by the ethics committee of Ruijin Hospital, School of Medicine, Shanghai Jiao Tong University, Shanghai, China and the Review Board exempted the requirement for written informed consent because this is a retrospective study that only focused on bacteria and did not affect the patients.

\section{Consent for publication \\ Not applicable.}

\section{Competing interests}

The authors declare that they have no competing interests.

\section{Author details}

${ }^{1}$ Department of Clinical Microbiology, Ruijin Hospital, Shanghai Jiaotong University School of Medicine, 197 Ruijin 2nd Road, Shanghai 200025, China. ${ }^{2}$ Department of Clinical Laboratory, Shanghai Pudong Hospital, Fudan University Pudong Medical Center, 2800 Gongwei Road, Huinan Town, Pudong, Shanghai 201399, China. ${ }^{3}$ Department of Hospital infection control, Ruijin Hospital, Shanghai Jiaotong University School of Medicine, 197 Ruijin 2nd Road, Shanghai 200025, China.

Received: 18 April 2019 Accepted: 18 June 2019

Published online: 15 July 2019

\section{References}

1. Le Doare K, Heath PT. An overview of global GBS epidemiology. Vaccine. 2013;31(Suppl 4):D7-12.

2. Sigler K, Spizek J, Rezanka T. Medicinal use of Lincosamides and microbial resistance to them. Anti-Infective Agents in Medicinal Chemistry (Formerly â Current Medicinal Chemistry - Anti-Infective Agents). 2007;6(2):133-44.

3. Hoeksema H, Bannister B, Birkenmeyer RD, Kagan F, Magerlein BJ, Mackellar FA, Schroeder W, Slomp G, Herr RR. Chemical studies on Lincomycin. I. the structure of Lincomycin. J Am Chem Soc. 1964;86(19):195-209.

4. Allewelt M, Schüler P, Bölcskei PL, Mauch H, Lode H. Ampicillin + sulbactam vs. clindamycin \pm cephalosporin for the treatment of aspiration pneumonia and primary lung abscess. Clin Microbiol Infect. 2004;10(2):163-70.

5. Bartlett JG. Methicillin-resistant Staphylococcus aureus infections. Top HIV Med. 2008;16(5):151-5.

6. Johnson MD, Decker CF. Antimicrobial agents in treatment of MRSA infections. Dis Mon. 2008;54(12):793-800.

7. Huang K, Zhang Q, Song Y, Zhang Z, Zhang A, Xiao J, Jin M. Characterization of Spectinomycin resistance in Streptococcus suis leads to two novel insights into drug resistance formation and dissemination mechanism. Antimicrob Agents Chemother. 2016;60(10):6390-2.

8. Hawkins PA, Law CS, Metcalf BJ, Chochua S, Jackson DM, Westblade LF, Jerris R, Beall BW, McGee L. Cross-resistance to lincosamides, streptogramins a and pleuromutilins in Streptococcus agalactiae isolates from the USA. J Antimicrob Chemother. 2017;72(7):1886-92.

9. Achard A, Villers C, Pichereau V, Leclercq R. New Inu(C) gene conferring resistance to lincomycin by nucleotidylation in Streptococcus agalactiae UCN36. Antimicrob Agents Chemother. 2005;49(7):2716-9.

10. Bozdogan B, Berrezouga L, Kuo MS, Yurek DA, Farley KA, Stockman BJ, Leclerca R. A new resistance gene, linB, conferring resistance to lincosamides by nucleotidylation in enterococcus faecium HM1025. Antimicrob Agents Chemother. 1999;43(4):925-9.

11. de Azavedo JC, McGavin M, Duncan C, Low DE, McGeer A. Prevalence and mechanisms of macrolide resistance in invasive and noninvasive group $B$ streptococcus isolates from Ontario, Canada. Antimicrob Agents Chemother. 2001;45(12):3504-8. 
12. Petinaki E, Guerin-Faublee V, Pichereau V, Villers C, Achard A, Malbruny B, Leclercq R. Lincomycin resistance gene Inu(D) in Streptococcus uberis. Antimicrob Agents Chemother. 2008;52(2):626-30.

13. Zhao Q, Wendlandt S, Li H, Li J, Wu C, Shen J, Schwarz S, Wang Y. Identification of the novel lincosamide resistance gene Inu(E) truncated by ISEnfa5-cfr-ISEnfa5 insertion in Streptococcus suis: de novo synthesis and confirmation of functional activity in Staphylococcus aureus. Antimicrob Agents Chemother. 2014;58(3):1785-8.

14. Arana DM, Rojo-Bezares B, Torres C, Alos Jl. First clinical isolate in Europe of clindamycin-resistant group B Streptococcus mediated by the $\operatorname{lnu}(B)$ gene. Rev Esp Quimioter. 2014;27(2):106-9.

15. Clinical and Laboratory Standards Institutes. Performance standards for antimicrobial susceptibility testing; 24th informational supplement, M100S24. Wayne,PA 2014

16. Elliott JA, Farmer KD, Facklam RR. Sudden increase in isolation of group $B$ streptococci, serotype $V$, is not due to emergence of a new pulsed-field gel electrophoresis type. J Clin Microbiol. 1998;36(7):2115-6.

17. Barton BM, Harding GP, Zuccarelli AJ. A general method for detecting and sizing large plasmids. Anal Biochem. 1995;226(2):235-40.

18. Sletvold H, Johnsen PJ, Wikmark OG, Simonsen GS, Sundsfjord A, Nielsen KM. Tn1546 is part of a larger plasmid-encoded genetic unit horizontally disseminated among clonal enterococcus faecium lineages. J Antimicrob Chemoth. 2010;65(9):1894.

19. Partridge SR, Kwong SM, Firth N, Jensen SO. Mobile genetic elements associated with antimicrobial resistance. Clin Microbiol Rev. 2018;31(4): e00088-17.

20. Verani JR, McGee L, Schrag SJ. Division of bacterial diseases NCfl, respiratory diseases CfDC, prevention: prevention of perinatal group B streptococcal disease--revised guidelines from CDC, 2010. MMWR Recomm Rep. 2010; 59(RR-10):1-36.

21. Castor ML, Whitney CG, Como-Sabetti K, Facklam RR, Ferrieri P, Bartkus JM, Juni BA, Cieslak PR, Farley MM, Dumas NB, et al. Antibiotic resistance patterns in invasive group B streptococcal isolates. Infect Dis Obstet Gynecol. 2008;2008:727505.

22. Lopes E, Fernandes T, Machado MP, Carriço JA, Melo-Cristino J, Ramirez M, Martins ER. Increasing macrolide resistance among Streptococcus agalactiae causing invasive disease in non-pregnant adults was driven by a single capsular-transformed lineage. Portugal, 2009 to 2015. 2018;23(21).

23. Betriu C, Culebras E, Gomez M, Rodriguez-Avial I, Sanchez BA, Agreda MC, Picazo $J$ J. Erythromycin and clindamycin resistance and telithromycin susceptibility in Streptococcus agalactiae. Antimicrob Agents Chemother. 2003;47(3):1112-4.

24. Yan Y, Hu H, Lu T, Fan H, Hu Y, Li G, Zhang X, Shi Y, Xia R. Investigation of serotype distribution and resistance genes profile in group B Streptococcus isolated from pregnant women: a Chinese multicenter cohort study. APMIS. 2016;124(9):794-9.

25. Faccone D, Lalonardi F, Abel S, Machain M, Errecalde L, Littvik A, Kauffman S, Galas M. Group WH-A, Corso a: multiple-clones of Streptococcus agalactiae harbouring InuB gene. J Infect Dev Ctries. 2010;4(9):580-2.

26. Montilla A, Zavala A, Caceres Caceres R, Cittadini R, Vay C, Gutkind G, Famiglietti A, Bonofiglio L, Mollerach M. Genetic environment of the Inu(B) gene in a Streptococcus agalactiae clinical isolate. Antimicrob Agents Chemother. 2014;58(9):5636-7.

27. Wang XM, Li XS, Wang YB, Wei FS, Zhang SM, Shang YH, Du XD. Characterization of a multidrug resistance plasmid from enterococcus faecium that harbours a mobilized bcrABDR locus. J Antimicrob Chemother. 2015;70(2):609-11.

28. Lozano C, Aspiroz C, Saenz Y, Ruiz-Garcia M, Royo-Garcia G, Gomez-Sanz E, Ruiz-Larrea F, Zarazaga M, Torres C. Genetic environment and location of the $\ln (\mathrm{a})$ and $\ln (\mathrm{B})$ genes in methicillin-resistant Staphylococcus aureus and other staphylococci of animal and human origin. J Antimicrob Chemother. 2012;67(12):2804-8.

29. Jiang H, Chen M, Li T, Liu H, Gong Y, Li M. Molecular characterization of Streptococcus agalactiae causing community- and hospital-acquired infections in Shanghai, China. Front Microbiol. 2016;7:1308.

30. Zhou K, Xie L, Han L, Guo X, Wang Y, Sun J. ICESag37, a novel integrative and conjugative element carrying antimicrobial resistance genes and potential virulence factors in Streptococcus agalactiae. Front Microbiol. 2017;8:1921

\section{Publisher's Note}

Springer Nature remains neutral with regard to jurisdictional claims in published maps and institutional affiliations.

\section{Ready to submit your research? Choose BMC and benefit from}

- fast, convenient online submission

- thorough peer review by experienced researchers in your field

- rapid publication on acceptance

- support for research data, including large and complex data types

- gold Open Access which fosters wider collaboration and increased citations

- maximum visibility for your research: over $100 \mathrm{M}$ website views per year

At $\mathrm{BMC}$, research is always in progress.

Learn more biomedcentral.com/submissions 